\title{
Intramuscular Aripiprazole in the Therapy of Acute Mania for More than 24 hrs
}

\author{
Arnim Quante ${ }^{1,2 \bowtie}$ and Jana Siedler ${ }^{1}$ \\ 1Department of Psychiatry and Psychotherapy, Friedrich von Bodelschwingh Clinic, Berlin, Germany \\ ${ }^{2}$ Department of Psychiatry and Psychotherapy, Charité-University Medicine Berlin, Campus Benjamin Franklin, Berlin, Germany
}

The use of atypical neuroleptics is common in the management of acute mania presenting with agitation und psychotic symptoms. ${ }^{1}$ Orally applied Aripiprazole has an antimanic and antipsychotic effect in patients with bipolar disorder ${ }^{2-4}$ but there is no mid and long term data (over $24 \mathrm{hrs}$ ) available for intramuscular (IM) injection of aripiprazole for the treatment of acute mania.

IM Aripiprazole is a safe and efficient therapy option for acute agitation. Repeated injections have been shown to raise the response rate. ${ }^{5,6}$ For IM aripiprazole the standard dose of one injection is $9.75 \mathrm{mg}$. Two additional doses may be applied during a $24 \mathrm{hr}$ period.

Here, we are presenting a case, in which the (off-label) application of aripiprazole over nine consecutive days treatment resulted in an improved mental state of a patient with acute mania.

A 55-year-old female was admitted for psychiatric inpatient treatment because of an acute mania with psychotic symptoms.

The patient had been diagnosed with a schizoaffective disorder (DSM-5 criteria) in the late 1980s. Her medication history included haloperidol, benperidol, perazine, flupentixole, amisulpride, olanzapine, quetiapine, risperidone, zuclopenthixol decanoate, clozapine, and lithium in different dosages and durations. Incompliance often led to hospitalization. It took over two months for a combination of olanzapine, valproate, and lithium to lead to a clinical improvement during the patient's most recent stay at a psychiatric hospital. It had also been possible to taper olanzapine before the patient was

\footnotetext{
Received: February 15, 2019 Revised: May 16, 2019

Accepted: June 10, 2019

$\triangle$ Correspondence: Arnim Quante, MD

Department of Psychiatry and Psychotherapy, Friedrich von Bodelschwingh Clinic, Landhausstrasse 33-35, Berlin 10717, Germany

Tel: +49-30-5472-7901, Fax: +49-30-5472-299500, E-mail: a.quante@fvbk.de

(c) This is an Open Access article distributed under the terms of the Creative Commons Attribution Non-Commercial License (https://creativecommons.org/licenses/bync/4.0) which permits unrestricted non-commercial use, distribution, and reproduction in any medium, provided the original work is properly cited.
}

discharged on that occasion.

The somatic history included a lithium-induced thyroid hypofunction, a steatosis hepatis as well as a psoriasis pustulosa palmoplantaris. The patient also suffers from obesity and tardive hyperkinesia.

Psychiatric examination revealed racing thoughts, delusions, megalomania, and euphoric mood but no hallucinations. Communication was impossible due to the patient's thought disorder and pressured speech. The patient refused to take any oral medication, the treatment was involuntary.

Initially, the patient was treated accordingly to the current pharmaceutical recommendation with olanzapine, intramuscularly, for five days including a one day break at the $4^{\text {th }}$ day. Due to a lack of clinical improvement, the therapeutic strategy was changed.

Before the treatment with aripiprazole was initiated, she had reached a score of 55 points in the Young Mania Rating Scale (YMRS), 42 points in the Positive and Negative Syndrome Scale (PANSS) positive scale and 38 points for PANSS negative scale. Treatment with Aripiprazole, $9.75 \mathrm{mg}$ intramuscularly, over nine days was associated with a reduction of YMRS by $30 \%$ (39 points), as well as of PANSS positive scale reduction of $26.2 \%$ ( 31 points) and PANSS negative scale by $29 \%$ ( 27 points). On day 8 of treatment, the serum level of aripiprazole was $120 \mu \mathrm{g} / \mathrm{L}$. We did not observe any side effects. As the patient continued refusing orally applied medication and to minimize the risk factors of continuous IM applications, we initiated treatment with a long-acting antipsychotic (olanzapine pamoate) in combination with intravenous valproate, because of the well-known effects during the last hospital stay. After nearly 3 months of treatment with valproic acid and olanzapine pamoate, the patient fulfilled the remission criteria. The valproic acid was tapered out after remission.

This case demonstrates the use of IM aripiprazole in a midterm (over $24 \mathrm{hrs}$ ) antimanic treatment of severe mania. Because of olanzapine's mean half-life of approx. $30 \mathrm{hrs}$ it is un- 
likely that the clinical improvement that we observed in the patient reported here under treatment with aripiprazole over nine days was associated with the pretreatment with olanzapine.

Our case presented here indicates that an application of IM aripiprazole for more than $24 \mathrm{hrs}$ can be safe, and that treatment with IM aripiprazole in manic episodes might be a future routine treatment for patients refusing oral medication.

However, our observations should be interpreted with caution, as the effects noted were limited to a single case. Therefore, further research, particularly a randomized controlled trial of the efficacy and safety of IM aripiprazole in acute mania, would be needed. However, there is no (published) midterm data about the toxicology for the repeated use of IM aripiprazole, so the this work has to be done before.

\section{Acknowledgments}

We thank Sara Zeugmann for revision of manuscript for intellectual content.

\section{Conflicts of Interest}

The authors have no potential conflicts of interest to disclose.

\section{Author Contributions}

Conceptualization: Arnim Quante. Data curation: Jana Siedler. Formal analysis: Arnim Quante. Investigation: Arnim Quante. Methodology: Arnim
Quante. Project administration: Arnim Quante. Supervision: Arnim Quante. Validation: Arnim Quante. Writing_original draft: Arnim Quante, Jana Siedler. Writing_review \& editing: Arnim Quante.

\section{ORCID iDs}

Arnim Quante https://orcid.org/0000-0002-1114-5024

\section{REFERENCES}

1. Allen MH, Currier GW. Use of restraints and pharmacotherapy in academic psychiatric emergency services. Gen Hosp Psychiatry 2004;26: 42-49.

2. Keck PE, Orsulak PJ, Cutler AJ, Sanchez R, Torbeyns A, Marcus RN, et al. Aripiprazole monotherapy in the treatment of acute bipolar I mania: a randomized, double-blind, placebo- and lithium-controlled study. J Affect Disord 2009;112:36-49.

3. Smith LA, Cornelius V, Warnock A, Tacchi MJ, Taylor D. Pharmacological interventions for acute bipolar mania: a systematic review of randomized placebo-controlled trials. Bipolar Disord 2007;9:551-560.

4. Suppes T, Eudicone J, McQuade R, Pikalov A 3rd, Carlson B. Efficacy and safety of aripiprazole in subpopulations with acute manic or mixed episodes of bipolar I disorder. J Affect Disord 2008;107:145-154.

5. Zimbroff DL, Marcus RN, Manos G, Stock E, McQuade RD, Auby P, et al. Management of acute agitation in patients with bipolar disorders: efficacy and safety of intramuscular aripiprazole. J Clin Psychopharmacol 2007;27:171-176.

6. Ostinelli EG, Jajawi S, Spyridi S, Sayal K, Jayaram MB. Aripiprazole (intramuscular) for psychosis-induced aggression or agitation (rapid tranquillisation). Cochrane Database Syst Rev 2018;1:CD008074. 